\title{
Shining Emitter in Stable Host: Design Halide Perovskite Scintillators for X-Ray Imaging from Commercial Concept
}

Fei Cao, ${ }^{1}$ Dejian Yu, ${ }^{1}$ Wenbo Ma, ${ }^{2}$ Xiaobao Xu $,{ }^{*}, 1$ Bo Cai, ${ }^{1}$ Yang (Michael) Yang, ${ }^{2}$ Sinan Liu, ${ }^{3}$ Lunhua He, ${ }^{4}$ Yubin Ke, ${ }^{4}$ Si Lan, ${ }^{3}$ Kwang-Leong Choy, ${ }^{5}$ Haibo Zeng*,1

1 Institute of Optoelectronics \& Nanomaterials, MIIT Key Laboratory of Advanced Display Materials and Devices, College of Materials Science and Engineering, Nanjing University of Science and Technology, Nanjing 210094, China.

2 State Key Laboratory of Modern Optical Instrumentation, College of Optical Science and Engineering, Zhejiang University, Hangzhou, Zhejiang 310007, China.

3 Herbert Gleiter Institute of Nanoscience, School of Materials Science and Engineering, Nanjing University of Science and Technology, 200 Xiaolingwei Avenue, Nanjing 210094, PR China

4 China Spallation Neutron Source, Dongguan Branch, Institute of High Energy Physics, Chinese Academy of Sciences, Dongguan 523803, China.

5 Institute for Materials Discovery, University College London, Roberts Building, Malet Place, London, WC1E 7JE, United Kingdom

*E-mail: xiaobaoxu@njust.edu.cn; zeng.haibo@njust.edu.cn 
Abstract: Halide perovskite (HP) nanocrystals (NCs) have recently shown great potential for $\mathrm{X}$-ray detection and imaging. However, the practical application is still a long way to go with lots of technical requirements waiting to be fulfilled, including structure optimization, stability enhancement, and cost reduction. A design principle in this beginning stage is urgently needed but still lacking. Herein, with an "emitter-in-matrix" principle refined from commercial scintillators, $\mathrm{CsPbBr}_{3} @ \mathrm{Cs}_{4} \mathrm{PbBr}_{6}$ with emissive $\mathrm{CsPbBr}_{3}$ NCs embedded inside solid-state $\mathrm{Cs}_{4} \mathrm{PbBr}_{6}$ host is brought to $\mathrm{X}$-ray sensing and imaging. The $\mathrm{Cs}_{4} \mathrm{PbBr}_{6}$ matrix not only enhances the attenuation of X-rays but also dramatically improves the stability of $\mathrm{CsPbBr}_{3} \mathrm{NCs}$. A favorable optical design with the $\mathrm{Cs}_{4} \mathrm{PbBr}_{6}$ matrix being transparent to the emission from $\mathrm{CsPbBr}_{3} \mathrm{NCs}$ enables efficient light output. As a result, stable and sensitive scintillation response to X-ray signals is demonstrated with superior linearity and ultrahigh time resolution. In order to show the huge potential for practical application, X-ray imaging using a large-area film $(360 \mathrm{~mm} \times 240 \mathrm{~mm}$ ) by blade-coating technique is carried out to obtain a high-quality image of human eye-invisible interior structures. In addition to the above advantages in optics, $\mathrm{CsPbBr}_{3} @ \mathrm{Cs}_{4} \mathrm{PbBr}_{6}$ also enjoys facile solution synthesis with large scalability, excellent repeatability and low cost.

Keywords: $\mathrm{x}$-ray imaging, scintillator, halide perovskite, $\mathrm{CsPbBr}_{3} @ \mathrm{Cs}_{4} \mathrm{PbBr}_{6}$, zerodimensional perovskite 
TOC graphic

\section{$X$-ray imaging}

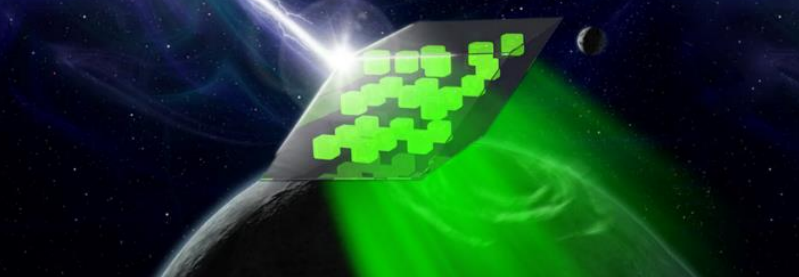


X-rays are high-energy electromagnetic radiation with a strong penetrability, therefore it can be used to detect inner situations that cannot be seen by human eyes. Since the discovery of Xray in 1895 by Wilhelm Röntgen, ${ }^{1}$ it has been widely applied in multiple supremely important fields, including diagnostic radiology, ${ }^{2}$ non-destructive testing, ${ }^{3}$ safety monitoring,${ }^{4}$ nuclear or radiation prevention and so on. ${ }^{5}$ The X-ray irradiation detection can be classified into two types: 1) a direct way by semiconductors $;{ }^{6}$ ) an indirect way using scintillators. ${ }^{7}$ Although the direct detectors (a-Se, $\mathrm{HgI}_{2}, \mathrm{CdTe}, \mathrm{CdZnTe}$, et al.) are renowned for high resolution, ${ }^{8}$ the response rate is usually low. Furthermore, the difficulties in fabricating large-sized wafer with small noise current but large $\mu \tau$ (mobility-lifetime) product still impose impediment in obtaining satisfactory price/performance ratio. ${ }^{9}$ In contrast, scintillators that downconvert high-energy rays into ultraviolet-visible (UV-vis.) light for indirect sensing of X-rays, are more industrially feasible with low cost, rich choices for customization, and flexible combination with commercially-mature sensing arrays (such as amorphous $\mathrm{Si}$ photodiodes, TFT arrays, photomultiplier tubes (PMTs), complementary metal-oxide semiconductor (CMOS), silicon avalanche photodiodes or charge-coupled devices (CCDs)) for X-ray imaging, ${ }^{10}$ therefore have attracted increasing research attention.

The strong penetration and radiation damage should be taken into consideration when designing scintillators, hence the stable forms of thick film (CsI:Tl for example) or bulk crystal are widely adopted in market. However, the film was fabricated by low-pressure thermal evaporation, ${ }^{11,12}$ and bulk crystals are widely grown by Czochralski method with an ultrahigh processing temperature over $1700{ }^{\circ} \mathrm{C}$, all these processes would result in high manufacture cost. ${ }^{13}$ Moreover, when considering the well-known quantum size effect, one of the most important basic principles to endow materials with bright radioluminescence, ${ }^{14,15}$ evaporated films and bulk crystals do not usually own decent scintillation behavior. As a result, the combination of reliable stability and superior scintillation performance in scintillators is the key challenge in material design. 
That's where the "emitter-in-matrix" design priciple, refined from commercial scintillators, takes effect. Usually rare-earth dopants as emitting centers are incorporated into crystal host to tackle the contradiction abovementioned, thereby producing the most-widely used scintillators including CsI:Tl, $\mathrm{NaI}: \mathrm{Tl}, \mathrm{Gd}_{2} \mathrm{O}_{2} \mathrm{~S}: \mathrm{Tb}, \mathrm{LaBr}_{3}: \mathrm{Ce}, \mathrm{LaCl}_{3}: \mathrm{Ce}, \mathrm{CaI}_{2}: \mathrm{Eu}, \mathrm{CaF}_{2}: \mathrm{Eu}$ and so on. ${ }^{16-21}$ Alternatively, these years have witnessed the prosperous development of fluorescent nanomaterials with low-temperature solution synthesis, higher quantum yields (QYs), narrower linewidth, and tunable emissions to replace rare-earth emitters in the next-generation scintillation technique. ${ }^{22-26}$ However, after developing so many kinds of nanomaterials, they have yet to be applied in the marke to date. The market is the most honest referee to inform the commercial feasibility, the failure of nanomaterials in scintillators can be ascribed to their rapid degradation upon irradiation, ${ }^{26,27}$ as well as the easy formation of nonradiative recombination paths to compromise the optical properties. ${ }^{28}$

Recently, a star material known as halide perovskite (HP), owning superior optoelectronic properties and containing heavy element $\mathrm{Pb},{ }^{29-33}$ was demonstrated to be efficient $\mathrm{X}$-ray sensors. Firstly the direct strategy was explored, ${ }^{34-40}$ but soon the indirect method using HP materials as scintillators was presented to show facility, better response rate, and comparable resolution. ${ }^{41}$, ${ }^{42}$ HP single crystals have presented respectable scintillation behavior but only at a very low temperature $(<130 \mathrm{~K})$, which is less practical and is unikely to popularize. ${ }^{43} \mathrm{In}$ comparison, HP nanocrystals (NCs) are more promising with admirable scintillation performance at room temperature, ${ }^{42,44}$ however, the problem is that they suffer from predictable poor stability to Xray irradiation not only because of their intrinsic high sensitivity to multiple environmental species including light, heat, and moisture, ${ }^{45-51}$ but also the well-revealed aggregation and phase transition issues. ${ }^{52-55}$ Thus, achieving both high scintillation performance and reliable stability upon X-ray irradiation in HPs is still effortful.

In this work, following the "emitter-in-matrix" designing concept refined from commercial scintillators, the $\mathrm{CsPbBr}_{3} @ \mathrm{Cs}_{4} \mathrm{PbBr}_{6}$ system with $\mathrm{CsPbBr}_{3}$ NCs embedded inside $\mathrm{Cs}_{4} \mathrm{PbBr}_{6}$ 
crystal matrix is explored for X-ray sensing and imaging. The benefits of such design are comprehensively introduced: 1) The $\mathrm{Cs}_{4} \mathrm{PbBr}_{6}$ matrix is not only to enhance the attenuation of $\mathrm{X}$-ray but also to greatly improve the stability of the embedded $\mathrm{CsPbBr}_{3} \mathrm{NCs}$. 2) At the same time, the wide-bandgap $\mathrm{Cs}_{4} \mathrm{PbBr}_{6}$ is transparent to the green emission of $\mathrm{CsPbBr}_{3} \mathrm{NCs}$ for efficient light output; 3) The delicate $\mathrm{CsPbBr}_{3} @ \mathrm{Cs}_{4} \mathrm{PbBr}_{6}$, however, enjoys facile solution synthesis with large scalability, excellent repeatability and low-cost fabrication, a high QY up to 60\%. As a result, the $\mathrm{CsPbBr}_{3} @ \mathrm{Cs}_{4} \mathrm{PbBr}_{6}$ shows scintillation response to $\mathrm{X}$-rays with excellent linearity and ultrashort decay time, which ensures low-dose sensing and high-quality imaging. Finally, via a facile and non-vacuum blade coating technique, a large-area film with a size up to $360 \mathrm{~mm} \times 240 \mathrm{~mm}$ is fabricated as an X-ray screen, by which a clear image of invisible interior structure is presented with high quality to show its great potential for practical use.

\section{Results/Discussion}

\section{Design of HP scintillators from the "emitter-in-matrix" principle}

The "emitter-in-matrix" design principle of scintillators toward X-ray sensing can be summed up as the following three aspects (Figure 1a): 1) The emitter should contribute to highefficiency radioluminescence; 2) The matrix is required for not only stopping the X-rays but also high material stability; 3) The host should be optically transparent to the emission from the embedded emitters for supressing photon loss. Figure $1 \mathrm{~b}$ displays the typical emitter-in-matrix structure of commercial scintillators, in which rare-earth elements are usually used as the emitter, CsI: Tl for example, which is the most widely used thin film scintillator. Despite the adequate performance in these scintillators, the high-temperature procedures are quite complicated and expensive. ${ }^{56,57}$

HP NCs have recently been reported to be potential cost-effective scintillators for highperformance X-ray sensing. Significantly, while pure HP NCs suffer from the notorious 
instability issue, ${ }^{58}$ a system known as $\mathrm{CsPbBr}_{3} @ \mathrm{Cs}_{4} \mathrm{PbBr}_{6}$, where $\mathrm{CsPbrr}_{3}$ NCs are embedded into $\mathrm{Cs}_{4} \mathrm{PbBr}_{6}$ matrix exactly following the "emitter-in-matrix" design principle (Figure 1c), has greatly encouraged the community with enhanced stability and comparable optical properties with pure $\mathrm{CsPBrr}_{3} \mathrm{NCs} .{ }^{59}$ It should first be mentioned that the origin of the bright green emission in $\mathrm{CsPbBr}_{3} @ \mathrm{Cs}_{4} \mathrm{PbBr}_{6}$ is still under debate, ${ }^{60}$ some groups ascribe the emission to $\mathrm{Cs}_{4} \mathrm{PbBr}_{6}$ itself by mid-gap defect centers or self-trapped excitons, ${ }^{61-68}$ while other groups believed it is the embedded but undiscovered $\mathrm{CsPbBr}_{3} \mathrm{NC}$ that accounts for the emission. ${ }^{59,69-}$ ${ }^{71}$ One of the focuses of this debate is whether there is $\mathrm{CsPbBr}_{3}$ inclusions in $\mathrm{Cs}_{4} \mathrm{PbBr}_{6}$, since typical structural characterizations of X-ray diffraction (XRD) and transmission electron microscopy (TEM) usually fail to identify impurities in $\mathrm{Cs}_{4} \mathrm{PbBr}_{6}$. Even though some groups reported the detection of $\mathrm{CsPbBr} 3$ phases, no convincing evidence was provided to tell if they are segregated $\mathrm{NCs}$ inside $\mathrm{Cs}_{4} \mathrm{PbBr}_{6}$ or phase-pure by-product. Therefore, researchers have recently turned to innovative methods such as pressure-induced phase transition and cathodoluminescence imaging. ${ }^{72,73}$
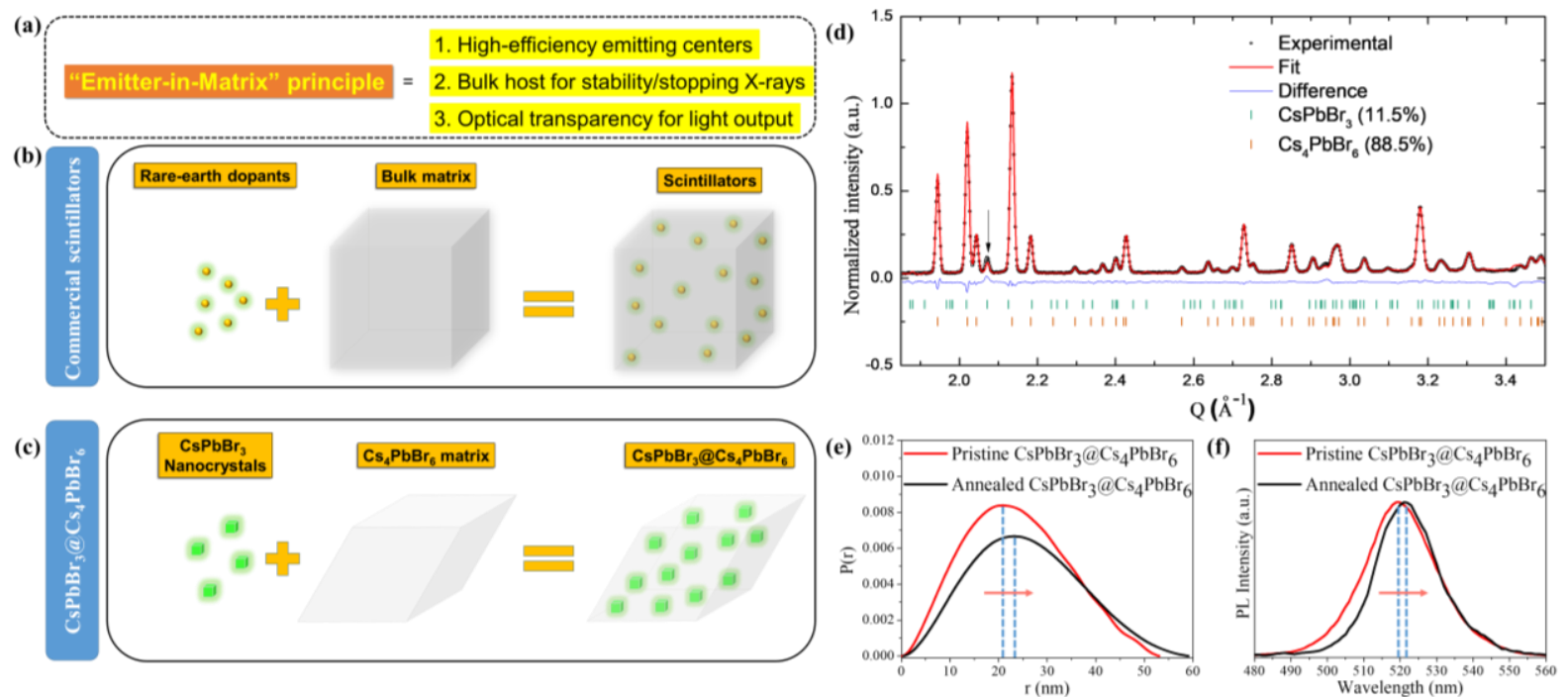

Figure 1. Design HP scintillators from the commercial "emitter-in-matrix" concept. (a) The three aspects of the "emitter-in-matrix" design principle. (b) Schematic illustration of the emitter-in-matrix structure of commercial scintillators (such as NaI: Tl). (c) Schematic view of the $\mathrm{CsPbBr}_{3} @ \mathrm{Cs}_{4} \mathrm{PbBr}_{6}$ structure, where $\mathrm{CsPbBr}_{3} \mathrm{NCs}$ are embedded into the $\mathrm{Cs}_{4} \mathrm{PbBr}_{6}$ matrix. (d) Neutron powder diffraction characterization to obtain the phase information and composition proportion of $\mathrm{CsPbBr}_{3}$ and $\mathrm{Cs}_{4} \mathrm{PbBr}_{6}$ in the $\mathrm{CsPbBr}_{3} @ \mathrm{Cs}_{4} \mathrm{PbBr}_{6}$ system. (e) The size distribution of $\mathrm{CsPbBr}_{3} \mathrm{NCs}$, PDDF, deduced from the SANS data. The red and black lines 
correspond to pristine $\mathrm{CsPbBr}_{3} @ \mathrm{Cs}_{4} \mathrm{PbBr}_{6}$ and annealed $\mathrm{CsPbBr}_{3} @ \mathrm{Cs}_{4} \mathrm{PbBr}_{6}$, respectively. (f) $\mathrm{PL}$ spectra of pristine and annealed $\mathrm{CsPbBr}_{3} @ \mathrm{Cs}_{4} \mathrm{PbBr}_{6}$. The annealing temperature was $250{ }^{\circ} \mathrm{C}$ and the annealing time was 30 mins.

Herein, neutron scattering technique was carried out to confirm the presence of $\mathrm{CsPbrr}_{3} \mathrm{NCs}$ inside the $\mathrm{Cs}_{4} \mathrm{PbBr}_{6}$ host with detailed phase information and size information. Firstly, neutron powder diffraction was conducted to obtain the phase information, the pristine and fitted data are shown in Figure 1d, the combination of hexagonal $\mathrm{Cs}_{4} \mathrm{PbBr}_{6}$ and orthorhombic $\mathrm{CsPbBr}_{3}$ matches perfectly with the experimental curve. Although the content of $\mathrm{CsPbBr}_{3}$ is very small (the molar fraction is $11.5 \%$ ), the characteristic peak marked by the black arrow unambiguously points out its presence. The detailed crystallographic data by the fitting are given in Table $\mathbf{S} 1$. Further, small-angle neutron scattering (SANS) characterization was carried out for the size information of the $\mathrm{CsPBr}_{3}$ phase. SANS is a technique that uses elastically scattered neutrons in a small-angle region to study mesoscale structures $(1 \mathrm{~nm} \sim 100 \mathrm{~nm})$ inside materials, the data is shown in Figure S1. Pair distance distribution function (PDDF) versus size distribution is presented in Figure 1e, the result shows that there are inhomogeneous nanostructures with the size of circa $20 \mathrm{~nm}$ within the $\mathrm{Cs}_{4} \mathrm{PbBr}_{6}$ host. Convincingly, the $518 \mathrm{~nm}$ emission and the 20 $\mathrm{nm}$ size matches well with the size-fluorescence relationship of $\mathrm{CsPbBr}_{3} \mathrm{NCs}$ in previous reports. ${ }^{74,75}$ To directly correlate the emitting centers with the nanostructures unveiled by SANS, the sample was annealed at $250{ }^{\circ} \mathrm{C}$ for comparison. As shown in Figure 1f, the high-temperature annealing causes an increase in the size of the nanostructures, and subsequently, a red-shift in the photoluminescence (PL) spectra. It should be noted that the size of $\sim 20 \mathrm{~nm}$ in $\mathrm{CsPbBr}_{3} \mathrm{NCs}$ means a weak quantum confinement, which may not fully explain the redshift of the emission. The redshift may also be partially linked to enhanced electron-photon coupling probably caused by the uncoordinated lattice expansion between the two phases under heat stress. What should also be kept in mind is that the presence of $\mathrm{CsPbBr}_{3}$ in $\mathrm{Cs}_{4} \mathrm{PbBr}_{6}$ does not deny the other proposals of the bright emission, on which more insightful researches are still required. 


\section{Enhanced X-ray attenuation and irradiation stability by the $\mathrm{Cs}_{4} \mathrm{PbBr}_{6}$ matrix}

When assessed as scintillators, the capability of attenuating X-rays is one of the most important parameters to be considered. In general, the X-ray attenuation can be described by an exponential function, $\mathrm{I} / \mathrm{I}_{0}=\exp (-\mathrm{kx})$, in which $\mathrm{k}$ is the attenuation coefficient, $\mathrm{x}$ is the depth of penetration (the details can be found in the Methods/Experimental section). The attenuation behavior is correlated to the density and the X-ray absorption of constituent atoms, and therefore can be estimated accordingly. The calculated X-ray attenuation coefficients (@50 keV) of $\mathrm{CsPbBr}_{3}, \mathrm{Cs}_{4} \mathrm{PbBr}_{6}, \mathrm{Si}, \mathrm{CsI}: \mathrm{Tl}$ and NaI: Tl are listed in Table $\mathbf{1}$ for comparison. The result shows that the $\mathrm{Cs}_{4} \mathrm{PbBr}_{6}$ host helps enhance the $\mathrm{X}$-ray attenuation when compared with pure $\mathrm{CsPbBr}_{3}$. It has been unveiled that there are exciton transfer and radiative transfer from $\mathrm{Cs}_{4} \mathrm{PbBr}_{6}$ host to the $\mathrm{CsPbBr}_{3} \mathrm{NCs}$ as in traditional scintillators with rare-earth activators, ${ }^{76,77}$ a discussion along with the photoluminescence excitation spectra (PLE) spectrum (@520 nm emission) in Figure $\mathbf{S} 2$ is provided in the Supporting Information. Besides, although slightly smaller than that of NaI: Tl and CsI:Tl, the coefficient is much larger than Si. The plots of Xray attenuation are shown and compared in Figure 2a. For the X-ray with $22 \mathrm{keV}$ peak intensity in our experiment, the thickness of $\mathrm{Cs}_{4} \mathrm{PbBr}_{6}$ required to attenuate $99.5 \% \mathrm{X}$-ray intensity is estimated to be $424 \mu \mathrm{m}$, which can be reached by mature film preparation techniques such as blade coating.

Another contribution of $\mathrm{Cs}_{4} \mathrm{PbBr}_{6}$ matrix is to enhance the irradiation endurance of emitting $\mathrm{CsPbBr}_{3}$ NCs. Pure $\mathrm{CsPbBr}_{3}$ NCs suffer from the issues of phase transition and even aggregation upon light irradiation. ${ }^{52-55}$ Figure $2 \mathrm{~b}$ displays the schematic illustration of this dynamic process. The advantage of the $\mathrm{CsPbBr}_{3} @ \mathrm{Cs}_{4} \mathrm{PbBr}_{6}$ structure is that the $\mathrm{Cs}_{4} \mathrm{PbBr}_{6}$ matrix can help to stabilize the $\mathrm{CsPbBr}_{3}$ emitting centers with passivating the highly-active surface of $\mathrm{CsPbBr}_{3} \mathrm{NCs}$ and inhibiting the isolated $\mathrm{CsPbBr}_{3}$ NCs from aggregation, as is illustrated in Figure 2c. Moreover, the emitter-in-matrix structure protects the interior $\mathrm{CsPbBr}_{3}$ 
NCs from environmental species such as moisture and oxygen, which have been verified to accelerate degradation under irradiation. ${ }^{78}$ We then compared the irradiation stability of pure $\mathrm{CsPbBr}_{3} \mathrm{NCs}$ (Figure S3, from hot injection method ${ }^{79}$ ) and the $\mathrm{CsPbBr}_{3} @ \mathrm{Cs}_{4} \mathrm{PbBr}_{6}$. Since long-term X-ray irradiation is not executable in lab for safety sake, ultraviolet (UV) irradiation test was carried out instead. The irradiation stress was set as $30 \mathrm{~W}$ and the testing time was $4 \mathrm{~h}$, during which the structure and PL were traced to evaluate the functionality retention. The XRD patterns are shown in Figure 2d, the characteristic peaks of $\mathrm{CsPbBr} 3 \mathrm{NCs}$ become narrower after the test, which points out a crystal size increase according to the Scherrer equation. In contrast, the pattern of $\mathrm{CsPbBr}_{3} @ \mathrm{Cs}_{4} \mathrm{PbBr}_{6}$ shows no change, reflecting its irradiation robustness in air. Figure 2e is the evolution of integrated PL intensity versus irradiation time. For the $\mathrm{CsPbBr}_{3} \mathrm{NCs}$, the emitting performance shows continuous decay under irradiation, and only $53 \%$ of the emission intensity remained after the test. Meanwhile, the red-shift in emission peak caused by aggregation-induced size increment was also observed (Figure S4). In the $\mathrm{CsPbBr}_{3} @ \mathrm{Cs}_{4} \mathrm{PbBr}_{6}$ sample, however, almost no change in PL spectra (Figure S5) and intensity were observed. This result confirms the significantly enhanced irradiation stability in $\mathrm{CsPbBr}_{3} @ \mathrm{Cs}_{4} \mathrm{PbBr}_{6}$ compared with pure $\mathrm{CsPbBr}_{3} \mathrm{NCs}$, which sets the precondition for the practical X-ray sensing and imaging application.

Table 1. Calculated attenuation coefficients of some scintillators (@50 keV X-ray). The corresponding unit of thickness is $\mathbf{m m}$.

\begin{tabular}{ll}
\hline Scintillator & Attenuation coefficient \\
\cline { 2 - 2 } $\mathrm{CsPbBr}_{3}$ & 3.58 \\
$\mathrm{Cs}_{4} \mathrm{PbBr}_{6}$ & 3.74 \\
$\mathrm{NaI}: \mathrm{Tl}$ & 3.84 \\
$\mathrm{CsI}: \mathrm{Tl}$ & 5.81 \\
$\mathrm{Si}$ & 0.12 \\
\hline
\end{tabular}

Note: $\mathrm{Cs}_{4} \mathrm{PbBr}_{6}$ denotes pure $\mathrm{Cs}_{4} \mathrm{PbBr}_{6}$ host rather than $\mathrm{CsPbBr}_{3} @ \mathrm{Cs}_{4} \mathrm{PbBr}_{6}$ host. 
(a)

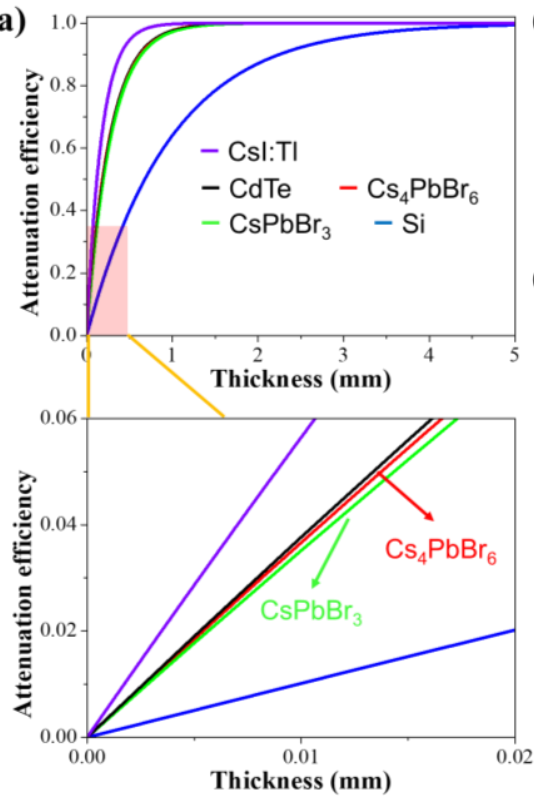

(b)

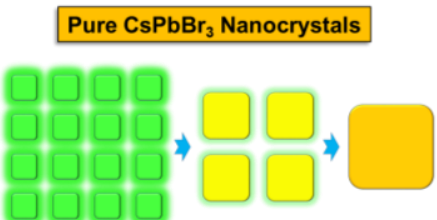

(d)
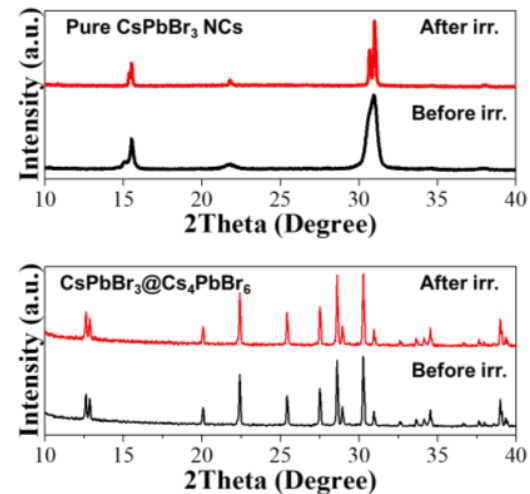

(c)

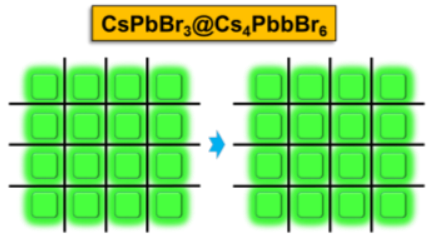

(e)

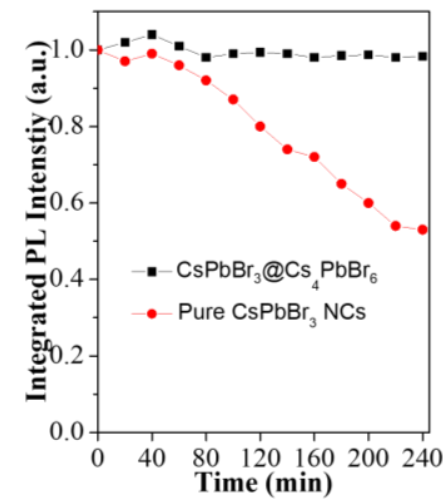

Figure 2. Enhanced X-ray attenuation and irradiation stability in $\mathrm{CsPbBr}_{3} @ \mathrm{Cs}_{4} \mathrm{PbBr}_{6}$ compared with pure $\mathrm{CsPbBr}_{3}$ NCs. (a) X-ray attenuating plot of $\mathrm{CsPbBr}_{3}$, $\mathrm{CsPbBr}_{3} @ \mathrm{Cs}_{4} \mathrm{PbBr}_{6}$, CsI:Tl, NaI:Tl and Si, respectively. The X-ray energy is $50 \mathrm{keV}$. (b) The aggregation effect causes fluorescence loss of the pure $\mathrm{CsPbBr}_{3} \mathrm{NCs}$ upon ultraviolet illumination. The green square is the initial HP NCs, the yellow square is intermediate state of the aggregated NCs, and the orange square represents the final state of the aggregated NCs. (c) The proposed robustness of $\mathrm{CsPbBr}_{3} @ \mathrm{Cs}_{4} \mathrm{PbBr}_{6}$ structure upon ultraviolet illumination. (d) The change of XRD patterns for pure $\mathrm{CsPbBr}_{3} \mathrm{NCs}$ and $\mathrm{CsPbBr}_{3} @ \mathrm{Cs}_{4} \mathrm{PbBr}_{6}$ after the irradiation test (30 W@365 nm for 4 h). (e) Evolution of the integrated PLintensity of $\mathrm{CsPbBr}_{3} @ \mathrm{Cs}_{4} \mathrm{PbBr}_{6}$ and pure $\mathrm{CsPbBr}_{3} \mathrm{NCs}$ during the test.

\section{Photon loss analysis from bandgap simulations}

The incident $\mathrm{X}$-rays excite $\mathrm{CsPbBr}_{3} \mathrm{NCs}$ to emit bright radioluminescence. To realize efficient photon output in typical "emitter-in-matrix" scintillators, the self-absorption by the matrix should be very low, i.e., the matrix should be optically transparent to the emission from the inside emitting centers. The proposed situation in $\mathrm{CsPbBr}_{3} @ \mathrm{Cs}_{4} \mathrm{PbBr}_{6}$ is shown in Figure 3a. The optical bandgap of $\mathrm{Cs}_{4} \mathrm{PbBr}_{6}$ was then estimated from density functional theory (DFT) calculation, the details of the calculation can be found in experimental section (Simulation Details). The result (Figure 3b) shows its bandgap reaches up to $3.8 \mathrm{eV}$, validating that the wide-bandgap $\mathrm{Cs}_{4} \mathrm{PbBr}_{6}$ matrix ensures the output of low-energy emission $(\sim 2.4 \mathrm{eV})$ from embedded $\mathrm{CsPbBr}_{3}$ NCs. Thus, it can be concluded that the $\mathrm{Cs}_{4} \mathrm{PbBr}_{6}$ matrix has negligible absorption on the internal $\mathrm{CsPbr}_{3}$ emitting photons. The corresponding absorption and 
radioluminescence (by X-rays with peak intensity of $22 \mathrm{keV}$ ) spectra of $\mathrm{CsPbBr}_{3} @ \mathrm{Cs}_{4} \mathrm{PbBr}_{6}$ are shown in Figure 3c. The absorption feature in the UV region matches well with the above simulated bandgap of $\mathrm{Cs}_{4} \mathrm{PbBr}_{6}$. Meanwhile, a single emission peak at $528 \mathrm{~nm}$ can be found in the radioluminescence spectrum. Interestingly, there is a redshift of $10 \mathrm{~nm}$ compared with that of $\mathrm{CsPbBr}_{3} @ \mathrm{Cs}_{4} \mathrm{PbBr}_{6}$ (peaked at 518 nm, Figure 1f). This redshift reduces the overlap of the radioluminescnece and absorption spectra, hence lowering the self-absorption of $\mathrm{CsPbr}_{3}$ inclusions themselves to further ensure efficient light output.

(a)

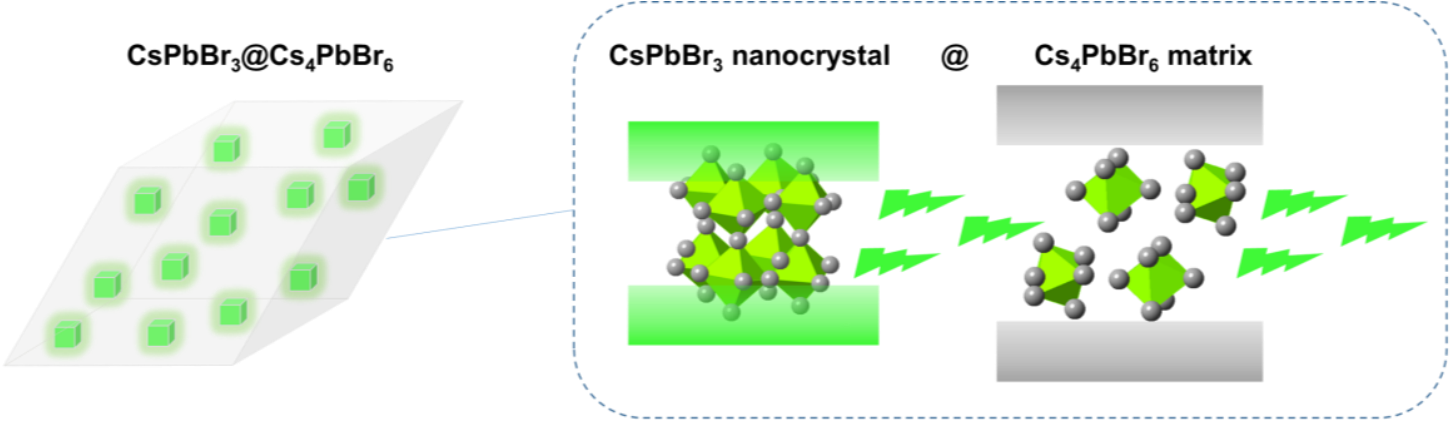

(b)

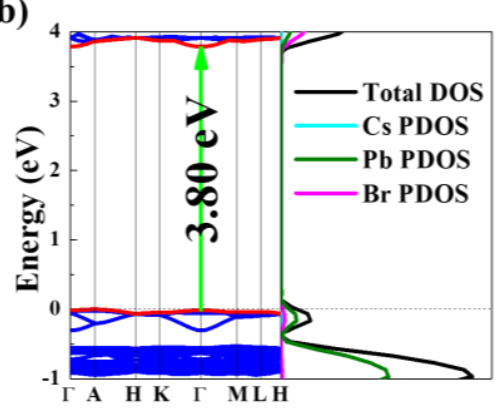

(c)

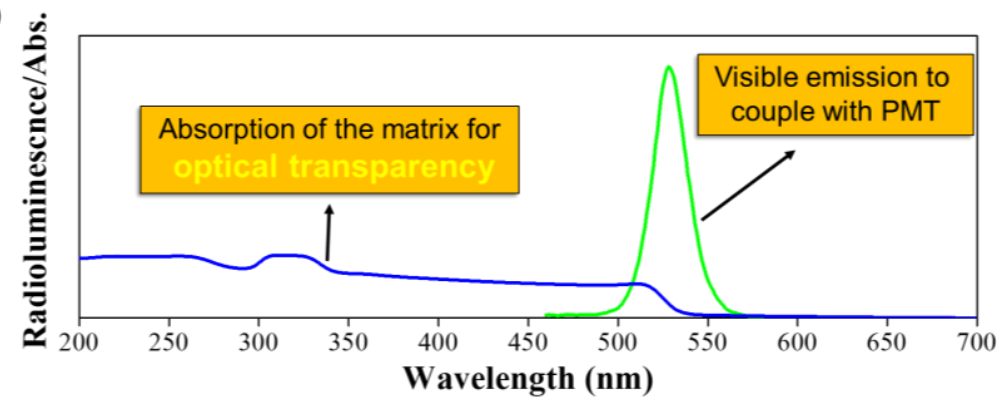

Figure 3. Transparent Cs4PbBr6 matrix enabling efficient light output. (a) Schematic view of the bandgap of the $\mathrm{CsPbBr}_{3}$ core and the $\mathrm{Cs}_{4} \mathrm{PbBr}_{6}$ matrix. (b) DFT simulation of the bandgap of the $\mathrm{Cs}_{4} \mathrm{PbBr}_{6}$ matrix. (c) Radioliminescence (X-ray@22 keV) and absorption spectrum analysis of the $\mathrm{CsPbBr}_{3} @ \mathrm{Cs}_{4} \mathrm{PbBr}_{6}$.

\section{X-ray sensing and imaging}

The efficient light output enables the sensing of weak X-ray signal, which is especially important in biomedical applications. Evidence of radiation-induced cancer risk at a dose above $100 \mathrm{mSv}$ (equals to $100 \mathrm{mGyair}$ ) shows that an estimation of $\sim 2 \%$ of the cancers could be related to CT radiation in the United States $(2007) .{ }^{80}$ Keep this in mind, the radioluminescence response of the $\mathrm{CsPbBr}_{3} @ \mathrm{Cs}_{4} \mathrm{PbBr}_{6}$ with a low X-ray dose was firstly tested. When combined with 
polymer (polystyrene here, termed as PS in the following), the film of $\mathrm{CsPbBr}_{3} @ \mathrm{Cs}_{4} \mathrm{PbBr}_{6}$ can be deposited with high thickness even up to centimeter-scale to fully absorb X-rays. The radioluminescence response is enhanced upon increasing X-ray irradiation as shown in Figure S6, and related discussion is offered in Figure S7. Significantly, excellent linearity can be found ranging from $93.75 \mu \mathrm{Gy}_{\text {air }} / \mathrm{s}$ to $1340.37 \mu \mathrm{Gy}$ air/s (Figure 4a), which means in this range the scintillation response and the radiation intensity can be predictably correlated. Significantly, this range is chosen referring to practical application, for example, the total irradiation dose for one-time chest computed tomography $(\mathrm{CT})$ is $0.5 \mathrm{mSv}-1 \mathrm{mSv}$, therefore, this linear response range fully meets the requirement of practical use with the exposure time of less than $1 \mathrm{~s}$.

(a)

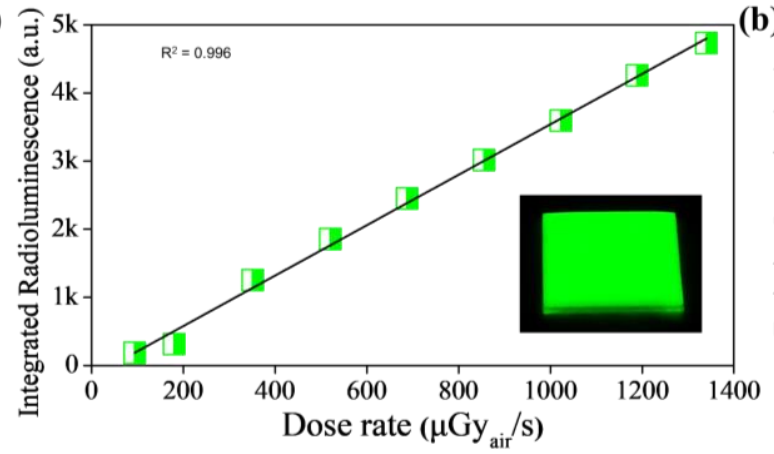

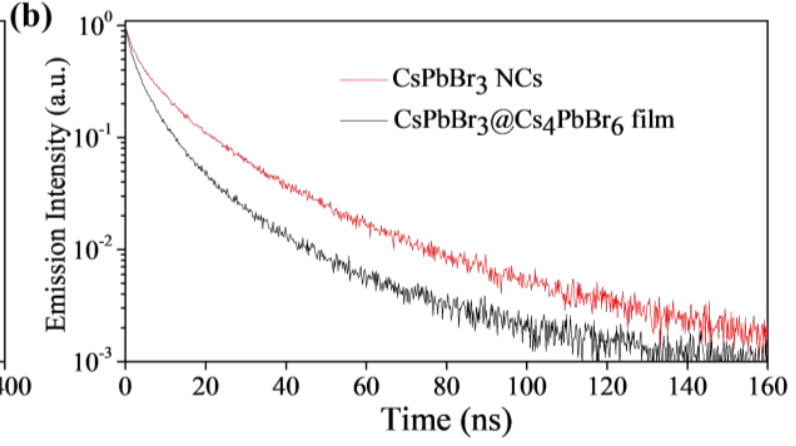

(c)

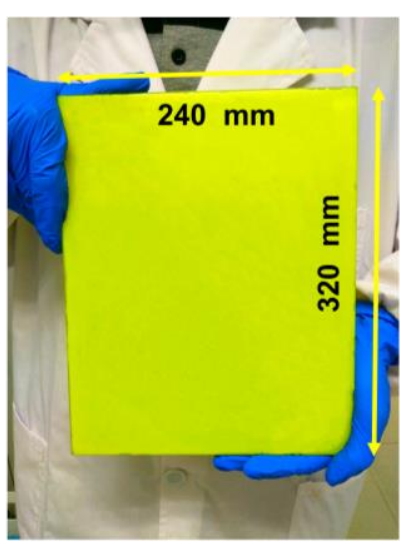

(d)

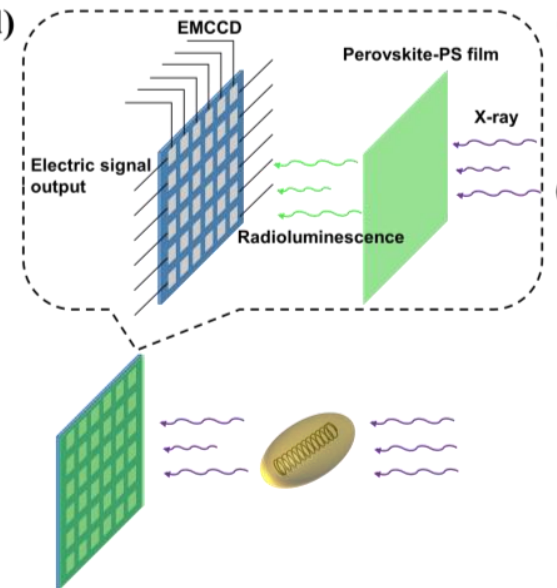

(e)

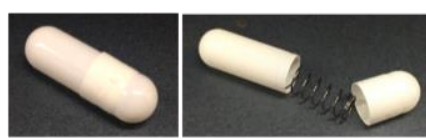

(f)

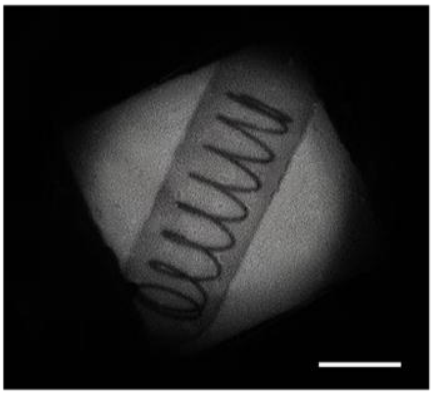

Figure 4. Scintillation behaviour and X-ray imaging of $\mathrm{CsPbBr}_{3} @ \mathrm{Cs}_{4} \mathrm{PbBr}_{6}$. (a) The linear relationship between the integrated $\mathrm{PL}$ intensity of the $\mathrm{CsPbBr}_{3} @ \mathrm{Cs}_{4} \mathrm{PbBr}_{6}$ film and the X-ray dose. Inset: the fluorescent film of $\mathrm{CsPbBr}_{3} @ \mathrm{Cs}_{4} \mathrm{PbBr}_{6}$ under X-ray excitation. (b) Emission decay spectra of the $\mathrm{CsPbBr}_{3} @ \mathrm{Cs}_{4} \mathrm{PbBr}_{6}$ film and the pure $\mathrm{CsPbBr}_{3} \mathrm{NCs}$, respectively. (c) Large-area film of the $\mathrm{CsPbBr}_{3} @ \mathrm{Cs}_{4} \mathrm{PbBr}_{6}$ by low-cost blade-coating technique. (d) A selfbuilt system for $\mathrm{X}$-ray imaging. The target material is placed between the $\mathrm{X}$-ray source and the sensing component. The sensing component is constructed by covering the $\mathrm{CsPbBr}_{3} @ \mathrm{Cs}_{4} \mathrm{PbBr}_{6}$ film onto an EMCCD. (e) Photographs of the target material-a capsule containing a spring inside. (f) The obtained image by the X-ray imaging, which clearly shows the human eyeinvisible metal spring inside. The scale bar is $1.5 \mathrm{~mm}$. 
Another important figure-of-merit of the scintillator is the decay time. As demonstrated above, the radioluminescence of commercial "emitter-in-matrix" based scintillators belongs to the emission of rare-earth elements, which suffer from slow decay rate that impedes their application in instant photography. In the $\mathrm{CsPbBr}_{3} @ \mathrm{Cs}_{4} \mathrm{PbBr}_{6}$ here, benefiting from additional confinement of $\mathrm{Cs}_{4} \mathrm{PbBr}_{6}$, the recombination dynamics for radiative emission is further accelerated. ${ }^{71}$ Figure $4 \mathrm{~b}$ is the emission decay characterization with ultraviolet excitation, while the lifetime in typical $\mathrm{CsPbBr}_{3} \mathrm{NCs}$ by the widely adopted hot injection method is $\sim 5 \mathrm{~ns}$, a faster decay rate with $\sim 3$ ns lifetime is observed in $\mathrm{CsPbBr}_{3} @ \mathrm{Cs}_{4} \mathrm{PbBr}_{6}$, the excitation fluence for the two samples are the same. The first-order decay is caused by geminate electron-hole recombination accelerated by the confinement effect in type I band alignment, the slow decays are probably caused by biexciton and Auger quenching. ${ }^{71}$ In Table 2, a series of the decay time of commercial scintillators for comparison is also listed, the $\mathrm{CsPbBr}_{3} @ \mathrm{Cs}_{4} \mathrm{PbBr}_{6}$ is found to own the fastest decay, which guarantees the high time-resolution for X-ray pulses. 
Table 2. Decay time data of the $\mathrm{CsPbBr}_{3} @ \mathrm{Cs}_{4} \mathrm{PbBr}_{6}$ scintillator as compared with some commerciallized scintillators. ${ }^{81,82}$

\begin{tabular}{ll}
\hline Scintillator & Decay time (ns) \\
\hline $\mathrm{NaI}: \mathrm{Tl}$ & 230 \\
$\mathrm{CsI}: \mathrm{Tl}$ & 1000 \\
$\mathrm{CsI}: \mathrm{Na}$ & 630 \\
$\mathrm{CsI}$ & 16 \\
$\mathrm{BGO}$ & 300 \\
$\mathrm{ZnWO}_{4}$ & 5000 \\
$\mathrm{CdWO}_{4}$ & 5000 \\
$\mathrm{BaF}_{2}: \mathrm{Ce}$ & 60 \\
$\mathrm{LaF}_{2}: \mathrm{Ce}$ & 27 \\
$\mathrm{CeF}_{2}$ & 40 \\
$\mathrm{YAlO}_{3}: \mathrm{Ce}$ & 30 \\
$\mathrm{Lu}_{2} \mathrm{SiO}_{5}: \mathrm{Ce}$ & 40 \\
$\mathrm{Y}_{3} \mathrm{Al}_{5} \mathrm{O}_{12}: \mathrm{Ce}$ & 65 \\
$\mathrm{Bi}_{4} \mathrm{Ge}_{3} \mathrm{O}_{12}$ & 300 \\
$\left(\mathrm{Y}_{12}, \mathrm{Gd}_{2} \mathrm{O}_{3}: \mathrm{Eu}\right.$ & 1000000 \\
$\mathrm{Gd}_{2} \mathrm{O}_{2} \mathrm{~S}: \mathrm{Pr}, \mathrm{Ce}, \mathrm{F}$ & 3000 \\
$\mathbf{C s P b B r}_{\mathbf{3}} @ \mathbf{C s} \mathbf{P b B r}_{\mathbf{6}}$ & $\mathbf{3}$ \\
\hline
\end{tabular}

Ultimately, to further verify its potential for practical X-ray imaging, a large-area film with the size up to $320 \mathrm{~mm} \times 240 \mathrm{~mm}$ was fabricated with ease by facile blade coating as shown in Figure 4c. A system illustrated in Figure 4d was built to show the X-ray imaging capability of the $\mathrm{CsPbBr}_{3} @ \mathrm{Cs}_{4} \mathrm{PbBr}_{6}$. The target material was placed between the X-ray source and the detecting component. Herein, a capsule containing a metal spring inside is used (Figure 4e), the inside spring cannot be seen by human eyes. When exposed to X-ray irradiation, the inside metal spring affords stronger X-ray attenuation than the capsule, therefore causing spatial intensity contrast. The signal contrast can be translated by the $\mathrm{CsPbBr}_{3} @ \mathrm{Cs}_{4} \mathrm{PbBr}_{6}$ film into difference of radioluminescence intensity, which is then read out as an image via an electron multiplying charge-coupled device (EMCCD). The obtained image (Figure 4f) clearly shows the inside metal spring. And to evaluate the effect, imaging with commercial CsI:Tl was also carried out for comparison as shown in Figure S8. This result confirms the $\mathrm{CsPbBr}_{3} @ \mathrm{Cs}_{4} \mathrm{PbBr}_{6}$ 
here can be readily integrated into commercially-mature devices for X-ray sensing and imaging. The persistence of the $\mathrm{CsPbBr}_{3} @ \mathrm{Cs}_{4} \mathrm{PbBr}_{6}$ scintillator was tested further. The same imaging test was carried out every two months, during the test no encapsulation was conducted. As shown in Figure S9, the quality of the image remained high after 4 months, which points out the long-term reliability of $\mathrm{CsPbBr}_{3} @ \mathrm{Cs}_{4} \mathrm{PbBr}_{6}$ scintillator for X-ray imaging.

\section{Solution synthesis and preliminary cost analysis}

After comfirming the superior scintillation performance, cost is also taken into consideration for industrialization. The delicate $\mathrm{CsPbr}_{3} @ \mathrm{Cs}_{4} \mathrm{PbBr}_{6}$, however, enjoys facile, up-scalable, highly repeatable and low-cost solution synthesis. The illustration of the procedure can be found in Figure 5a. In brief, stoichiometric $\mathrm{CsBr}$ and $\mathrm{PbBr}_{2}$ were dissolved in dimethyl sulfoxide (DMSO) to form the precursor, then the precursor was directly mixed with preheated toluene $\left(120^{\circ} \mathrm{C}\right)$ that serves as antisolvent to force recrystallization of $\mathrm{CsPbBr}_{3} @ \mathrm{Cs}_{4} \mathrm{PbBr}_{6}{ }^{83} \mathrm{All}$ procedures were completed in open air. Figure $5 \mathrm{~b}$ is the large-scale synthesis with the yield of products reaching $>15$ grams from one-pot synthesis. The scanning electron microscopy (SEM) image is presented in Figure S10, A well-defined parallelepiped shape consistent with the crystallographic structure can be observed, ${ }^{64,}{ }^{84}$ which indicates a favorable crystallization process and high crystallinity. As a result, the $\mathrm{QY}$ of $\mathrm{CsPbBr}_{3} @ \mathrm{Cs}_{4} \mathrm{PbBr}_{6}$ products reaches up to $60 \%$. Notably, the size of the $\mathrm{CsPbBr}_{3} @ \mathrm{Cs}_{4} \mathrm{PbBr}_{6}$ particles is in the micron scale, which helps to prevent light scattering for efficient output. ${ }^{85}$ In addition to the convenient operation and rapid scalability, solution synthesis is also highly repeatable. The fabrication process 10 times to compare the corresponding PL spectra of the products. The result is presented in Figure S11, a perfect overlap can be observed, which indicates the superior reliability in the fabrication process for commercial synthesis. 
(a)

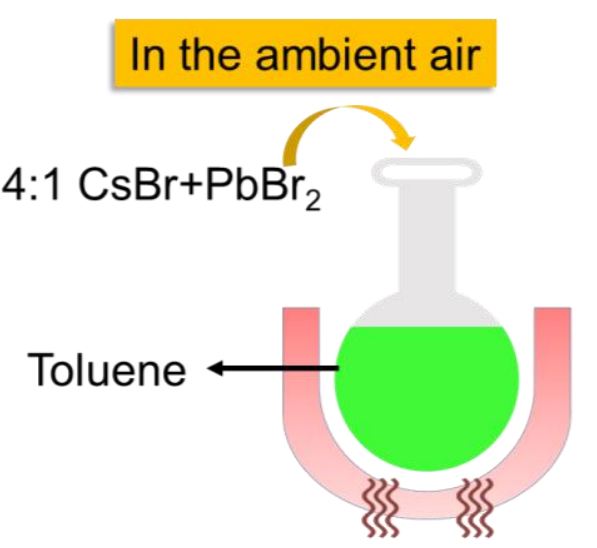

(c)

\begin{tabular}{|c|c|}
\hline YAP:Ce & $60 \$ / g$ \\
\hline YAG:Ce & $25 \$ / g$ \\
\hline LYSO & $8.4 \$ / g$ \\
\hline $\mathrm{CsPbBr}_{3} @ \mathrm{Cs}_{4} \mathrm{PbBr}_{6}$ & $3.1 \$ / g$ \\
\hline CsI(TI) & $2.5 \$ / g$ \\
\hline BGO & $2.0 \$ / \mathrm{g}$ \\
\hline
\end{tabular}

Figure 5. Design of commercial synthesis to obtain high-quality CsPbBr3@Cs4PbBr6. (a) Facile solution preparation of the $\mathrm{CsPbBr}_{3} @ \mathrm{Cs}_{4} \mathrm{PbBr}_{6}$. (b) Up-scale synthesis of the $\mathrm{CsPbBr}_{3} @ \mathrm{Cs}_{4} \mathrm{PbBr}_{6}$ with high QYs. (c) Cost/price comparison of the $\mathrm{CsPbBr}_{3} @ \mathrm{Cs}_{4} \mathrm{PbBr}_{6}$ and some commercial scintillators.

Figure 5c gives the preliminary cost analysis of $\mathrm{CsPbBr}_{3} @ \mathrm{Cs}_{4} \mathrm{PbBr}_{6}$ products to compare with the prices of some widely-used commercial scintillators. It should be noted that the price of these commercialized scintillators highly depends on customized processings, here the price is only for the crude ingots the same as $\mathrm{CsPbBr}_{3} @ \mathrm{Cs}_{4} \mathrm{PbBr}_{6}$ to ensure a fair comparison. The result shows that the cost of $\mathrm{CsPbBr}_{3} @ \mathrm{Cs}_{4} \mathrm{PbBr}_{6}$ is quite close to that of $\mathrm{BGO}\left(\mathrm{Bi}_{4} \mathrm{Ge}_{3} \mathrm{O}_{12}\right)$ and CsI:Tl, but is much cheaper than YAP: $\mathrm{Ce}\left(\mathrm{YAP}\right.$ is $\mathrm{YAlO}_{3}$ ), $\mathrm{YAG}: \mathrm{Ce}\left(\mathrm{YAG}\right.$ is $\mathrm{Y}_{3} \mathrm{Al}_{5} \mathrm{O}_{12}$ ), and LYSO $\left((\mathrm{Lu}, \mathrm{Y})_{2} \mathrm{SiO}_{5}: \mathrm{Ce}\right)$. If the scalability and processing are taken into considerations, the cost will be lowered further, which convinces us of the commercial competitiveness of the $\mathrm{CsPbBr}_{3} @ \mathrm{Cs}_{4} \mathrm{PbBr}_{6}$ scintillator.

\section{Conclusions}


In conclusion, we have fabricated $\mathrm{CsPbBr}_{3} @ \mathrm{Cs}_{4} \mathrm{PbBr}_{6}$ as scintillators for practical X-ray sensing and imaging. To clarify its commercial perspective, we evaluate the matrix from the commercial concepts, including material structure, stability, optical properties, and manufacture cost. The results indicate $\mathrm{CsPbBr}_{3} @ \mathrm{Cs}_{4} \mathrm{PbBr}_{6}$ hold a series of advantages over the traditional rare-element based scintillators. Finally, a large-area $\mathrm{CsPbBr}_{3} @ \mathrm{Cs}_{4} \mathrm{PbBr}_{6}$ film (360 $\mathrm{mm} \times 240 \mathrm{~mm}$ ) fabricated by blade-coating technique imaging screen shows high-quality Xray imaging. Sensitive scintillation response to X-ray signals is demonstrated with superior linearity and nanosecond scale decay. We have a reason to believe that the $\mathrm{CsPbBr}_{3} @ \mathrm{Cs}_{4} \mathrm{PbBr}_{6}$ scintillator is on its way to be the next generation X-ray imaging and detecting technology. Future work will focus on growing large-sized $\mathrm{CsPbBr}_{3} @ \mathrm{CsPbBr}_{4}$ crystals for the advancement of this class of scintillator.

\section{Methods/Experimental}

\section{Small-angle neutron scattering:}

In this work, SANS was performed on the Small Angle Neutron Scattering (SANS) instrument

at China Spallation Neutron Source (CSNS). The incident neutrons with wavelength of 1-9 were defined by a double-disc bandwidth chopper, which is collimated to the sample by a pair of apertures. The experiment used the sample to detector distance of $4 \mathrm{~m}$ and a sample aperture of $6 \mathrm{~mm}$. The $1 \mathrm{~m}$ square detector array composed of 120 linear He-3 gas tubes with the diameter of $8 \mathrm{~mm}$, which covers the Q-range between $0.01 \AA^{-1}$ and $1 \AA^{-1}$. The presented data correspond to $\sim 120$ min of data collection time for each sample (@50kW). Neutron data were corrected for background scattering (empty sample holder), transmission and detector efficiency, and set to absolute units. 
Chemicals for preparing CsPbBr $3 @ C_{4}$ PbBr $_{6}: \operatorname{CsBr}\left(\sim 99.5 \%\right.$, Aladdin), $\mathrm{PbBr}_{2}$ ( 99\%, MACKLIN), dymethyl sulfoxide (DMSO, 99.8\%, Aladdin), toluene ( $\geq 99.5 \%$, Shanghai Lingfeng Chemical Reagents Co., LTD), polystyrene (PS, Aldrich, average Mw 280, 000 by GPC).

Large-scale preparation of $\mathrm{Cs}_{\mathrm{PbBr}} @ \mathrm{Cs}_{4} \mathrm{PbBr}_{6}$ by solution method: All chemicals were purchased from Aladdin and used without further purification. For typical large-scale synthesis, $20 \mathrm{~mol} \mathrm{CsBr}$ and $5 \mathrm{~mol} \mathrm{PbBr}_{2}$ were dissolved in $100 \mathrm{ml}$ dimethyl sulfoxide (DMSO) to form precursor. The precursor was heated at $100{ }^{\circ} \mathrm{C}$, then $500 \mathrm{ml}$ toluene was added into the heated precursor as antisolvent to force the precipitation. The solution was then vigorously stirred for at least $2 \mathrm{~h}$ to ensure a complete reaction of the reagents. To extract the products, the solution was placed still until the particles quickly sink to the bottom, then the supernatant was discarded, and the precipitates were washed with toluene before centrifugation was carried out to extract the precipitates. The centrifugation-washing procedure was repeated several times before the products were sent for vacuum drying.

Fabrication of the CsPbBr $3 @ C_{4} \mathrm{PbBr}_{6} / \mathrm{PS}$ film: Firstly, polystyrene (PS) was dissolved in toluene to form a ropy solution. The abovementioned $\mathrm{CsPbBr}_{3} @ \mathrm{Cs}_{4} \mathrm{PbBr}_{6}$ powder was grinded to uniformize and reduce the size of $\mathrm{CsPbBr}_{3} @ \mathrm{Cs}_{4} \mathrm{PbBr}_{6}$ particles. Then the ground $\mathrm{CsPbBr}_{3} @ \mathrm{Cs}_{4} \mathrm{PbBr}_{6}$ was added into the PS/toluene solution and vigorously stirred, the concentration is $0.2 \mathrm{~g} / \mathrm{ml}$. After complete stirring for at least $10 \mathrm{~h}$, the solution was casted by blade coating, and dried naturally in the air to obtain a solid film.

Preparation of the CsPbBr 3 nanocrystals: The synthesis of $\mathrm{CsPbBr}_{3}$ nanocrystals basically follow the method reported in previous work, ${ }^{79}$ where the details can be found. 
Characterizations: A commercially available Amptek Mini-X tube with a Ag target and 4 W maximum power output was used as the X-ray source. The total X-ray dose was modulated by changing the current of the X-ray tube and the distance between the device and the X-ray source. The radiation dose rate was calibrated using a Radcal ion chamber dosimeter. A SPEX 8000 Mixer Mill was employed in this experiment; The XRD experiment were performed using Bruker D8 Advance XRD system; SEM images were captured by a Quant 250FEG instrument; The reflectance and photoluminescence spectra were measured by a SHIMADZU UV-3600 UV-VIS-NIR spectrophotometer and a Cary Eclipse Fluorescence Spectrophotometer, respectively; The lifetimes of PL were detected by a homemade instrument with a $375 \mathrm{~nm}$ picosecond lasers; The photoluminescence (PL) quantum yield (QY) was obtained by a HORIBA Fluomax-4 spectrometer; All the device characterizations were conducted at room temperature in ambient air. For testing the photastability, $\mathrm{Cs}_{3} \mathrm{PbBr}_{3} @ \mathrm{Cs}_{4} \mathrm{PbBr}_{6}$ powders and pure $\mathrm{CsPbBr}_{3}$ nanocrystals were exposed under a UV lamp with a power of $30 \mathrm{~W}$ for $4 \mathrm{~h}$, the wavelength of the ligth is $365 \mathrm{~nm}$.

\section{Neutron powder diffraction:}

Neutron diffraction measurement was performed at the time of flight (TOF) general purpose powder diffractometer (GPPD) at China Spallation Neutron Source (CSNS). Decoupled poisoned hydrogen moderator (DPHM) is chosen in this measurement. The powder sample position is located in a vacuum chamber with a diameter of $1.2 \mathrm{~m}$. Neutron diffraction pattern was collected at romm temperature with wavelength from $0.1 \sim 4.9 \AA$. In consideration of $\mathrm{Q}=4 \Pi \sin \theta / \lambda$. Three detector banks (high-angle, $90^{\circ}$, low-angle) provide Q-range $0.22 \AA$ $125.66 \AA$.

Simulation details: All the DFT calculations were performed using the Vienna $a b$ initio simulation package (VASP), under periodic boundary conditions. ${ }^{86}$ The projector-augmented- 
wave $(\mathrm{PAW})$ potential with cesium $(\mathrm{Cs})$, lead $(\mathrm{Pb})$, and bromine $(\mathrm{Br})$ is described as valence electrons. ${ }^{87}$ Geometry optimization and electronic band structure were carried out using the Perdew-Burke-Ernzerholf (PBE) exchange-correlation functional. ${ }^{88}$ A kinetic energy cutoff of $500 \mathrm{eV}$ was set on a grid of $6 \times 6 \times 4$ k-points for tetragonal $\mathrm{CsPbBr}_{3}$, and on a grid of $5 \times 5 \times 4 \mathrm{k}-$ points for hexagonal $\mathrm{Cs}_{4} \mathrm{PbBr}_{6}$.

\section{Calculation of the X-ray attenuation coefficients:}

A narrow beam of monoenergetic photons with an incident intensity $\mathrm{I}_{0}$, penetrating a layer of material with mass thickness $\mathrm{x}$ and density $\rho$, emerges with intensity I given by the exponential attenuation law:

$\mathrm{I} / \mathrm{I}_{0}=\exp \left[-(\mu / \rho)^{*} \mathrm{x}\right] \quad($ eq 1$)$

Where $\mathrm{I}_{0}$ is the initial intensity of the X-ray, I is the intensity of X-ray at the mass thickness of $\mathrm{x}, \rho$ is the density of the dense matter, $\mathrm{x}$ is defined as mass thickness per unit area and is obtained by multiplying the thickness $\mathrm{t}$ by the density $\rho$, i.e., $\mathrm{x}=\rho \mathrm{t}$. Therefore, eq 1 can be expressed as:

$\mathrm{I} / \mathrm{I}_{0}=\exp \left[-(\mu / \rho)^{*} \rho \mathrm{t}\right] \quad($ eq 2$)$

For compounds like $\mathrm{Cs}_{4} \mathrm{PbBr}_{6}$ and $\mathrm{CsPbBr}_{3}$, the value of mass attenuation coefficient, $\mu / \rho$, can be obtained according to simple additivity:

$\mu / \rho=\sum_{\mathrm{i} W \mathrm{i}}(\mu / \rho)_{\mathrm{i}} \quad($ eq 3$)$

where $w_{\mathrm{i}}$ is the fraction by weight of the $\mathrm{i}^{\text {th }}$ atomic constituent, and the $(\mu / \rho)_{\mathrm{i}}$ values of each atom can be obtained from the following URL: 
https://physics.nist.gov/PhysRefData/XrayMassCoef/tab3.html

\author{
Author information \\ Corresponding authors \\ *Email: xiaobaoxu@njust.edu.cn; \\ *Email: zeng.haibo@njust.edu.cn
}

\title{
Acknowledgement
}

This work was financially supported by the Natural Science Foundation of Jiangsu Province (BK20190443, BK20160815), Young Elite Scientists Sponsorship Program by Jiangsu CAST (JS19TJGC132574), Fundamental Research Funds for the Central Universities (30919011299, 30919011298), National Key R\&D Program of China (No. 2017YFA0305500), the National Natural Science Foundation of China (No. 11604152, 51672132), the National Natural Science Funds for Distinguished Young Scholars (61725402).

\section{Supporting information}

The Supporting Information is available free of charge via the Internet at http://pubs.acs.org. Phase information of $\mathrm{CsPbBr}_{3}$ and $\mathrm{Cs}_{4} \mathrm{PbBr}_{6}$ in the $\mathrm{CsPbBr}_{3} @ \mathrm{Cs}_{4} \mathrm{PbBr}_{6}$ system obtained by the neutron scattering characterizations; Small-angle neutron scattering data of $\mathrm{CsPbBr}_{3} @ \mathrm{Cs}_{4} \mathrm{PbBr}_{6}$; The comparison of PLE spectrum and absorption spectrum; TEM image of the as-prepared $\mathrm{CsPbBr}_{3}$ nanocrystals; Irradiation-induced degradation of pure $\mathrm{CsPbBr}_{3}$ nanocrystals; PL spectra of as-prepared $\mathrm{CsPbBr}_{3} @ \mathrm{Cs}_{4} \mathrm{PbBr}_{6}$ and that after the irradiation test (30 W@365 nm for $4 \mathrm{~h}$ ); Radioluminescence spectrum of the $\mathrm{Cs}_{\mathrm{PbBr}} @ \mathrm{Cs}_{4} \mathrm{PbBr}_{6}$ under increasing X-ray doses; Light yield evaluation by comparing with commercial CsI:Tl scintillator; X-ray imaging using CsI:Tl scintillator; X-ray imaging results using the $\mathrm{CsPbBr}_{3} @ \mathrm{Cs}_{4} \mathrm{PbBr}_{6}$ scintillator obtained every two months; SEM image of the $\mathrm{CsPbBr}_{3} @ \mathrm{Cs}_{4} \mathrm{PbBr}_{6}$, the scale bar is $10 \mu \mathrm{m}$; PL spectra of 10 batches of $\mathrm{CsPbBr}_{3} @ \mathrm{Cs}_{4} \mathrm{PbBr}_{6}$ to show the excellent repeatability of the solution synthesis. 


\section{References}

1. Nikl, M. Scintillation Detectors for X-Rays. Meas. Sci. Technol. 2006, 17, R37-R54.

2. Ay, M.R.; M. Shahriari; S. Sarkar; M. Adib; H. Zaidi. Monte Carlo Simulation of X-Ray Spectra in Diagnostic Radiology and Mammography Using MCNP4C. Phys. Med. Biol. 2004, 49, 4897-4917.

3. Hanke, R.; T. Fuchs; N. Uhlmann. X-Ray Based Methods for Non-Destructive Testing and Material Characterization. Nucl. Instrum. Methods Phys. Res., Sect. A 2008, 591, 14-18.

4. Borgese, L.; F. Bilo; R. Dalipi; E. Bontempi; L.E. Depero. Total Reflection X-Ray Fluorescence as A Tool for Food Screening. Spectrochim. Acta, Part B 2015, 113, 1-15.

5. O'Nions, K.; R. Pitman; C. Marsh. Science of Nuclear Warheads. Nature 2002, 415, 853-7.

6. Denes, P.; D. Doering; H.A. Padmore; J.-P. Walder; J. Weizeorick. A Fast, Direct X-Ray Detection Charge-Coupled Device. Rev. Sci. Instrum. 2009, 80, 083302.

7. Nagarkar, V.V.; S.R. Miller; S.V. Tipnis; A. Lempicki; C. Brecher; H. Lingertat. A New Large Area Scintillator Screen for X-Ray Imaging. Nucl. Instrum. Methods Phys. Res., Sect. B 2004, 213, 250-254.

8. Kasap, S.O.; J.A. Rowlands. Direct-Conversion Flat-Panel X-Ray Image Sensors for Digital Radiography. Proc. IEEE 2002, 90, 591-604.

9. Wei, H.; D. DeSantis; W. Wei; Y. Deng; D. Guo; T.J. Savenije; L. Cao; J. Huang. Dopant Compensation in Alloyed $\mathrm{CH}_{3} \mathrm{NH}_{3} \mathrm{PbBr}_{3-\mathrm{x}} \mathrm{Cl}_{\mathrm{x}}$ Perovskite Single Crystals for Gamma-Ray Spectroscopy. Nat. Mater. 2017, 16, 826-833.

10. Wei, H.; J. Huang. Halide Lead Perovskites for Ionizing Radiation Detection. Nat. Commun. 2019, 10, 1066.

11. Yao, D.L.; M. Gu; X.L. Liu; S.M. Huang; B. Liu; C. Ni. Fabrication and Performance of Columnar CsI(Tl) Scintillation Films with Single Preferred Orientation. IEEE Trans. Nucl. Sci. 2013, 60, 1632-1636.

12. Cha, B.K.; J.Y. Kim; T.J. Kim; C. Sim; G. Cho. Fabrication and Imaging Characterization of High Sensitive $\mathrm{CsI}(\mathrm{Tl})$ and $\mathrm{Gd}_{2} \mathrm{O}_{2} \mathrm{~S}(\mathrm{~Tb})$ Scintillator Screens for X-Ray Imaging Detectors. Radiat. Meas. 2010, 45, 742-745.

13. Weber, M.J. Inorganic Scintillators: Today and Tomorrow. J. Lumin. 2002, 100, 35-45. 14. Nirmal, M.; L. Brus. Luminescence Photophysics in Semiconductor Nanocrystals. Acc. Chem. Res. 1999, 32, 407-414. 
15. Mastronardi, M.L.; F. Maier-Flaig; D. Faulkner; E.J. Henderson; C. Kübel; U. Lemmer; G.A. Ozin. Size-Dependent Absolute Quantum Yields for Size-Separated Colloidally-Stable Silicon Nanocrystals. Nano Lett. 2012, 12, 337-342.

16. Nagarkar, V.V.; T.K. Gupta; S.R. Miller; Y. Klugerman; M.R. Squillante; G. Entine. Structured CsI(Tl) Scintillators for X-Ray Imaging Applications. IEEE Trans. Nucl. Sci. 1998, 45, 492-496.

17. Yanagida, T. Study of Rare-Earth-Doped Scintillators. Opt. Mater. 2013, 35, 1987-1992. 18. Jung, I.D.; M.K. Cho; S.M. Lee; K.M. Bae; P.G. Jung; C.H. Lee; J.M. Lee; S. Yun; H.K. Kim; S.S. Kim; J.S. Ko. Flexible $\mathrm{Gd}_{2} \mathrm{O}_{2} \mathrm{~S}$ :Tb Scintillators Pixelated with Polyethylene Microstructures for Digital X-Ray Image Sensors. J. Micromech. Microeng. 2008, 19, 015014.

19. Loef, E.V.D.v.; P. Dorenbos; C.W.E.v. Eijk; K. Krämer; H.U. Güdel. High-EnergyResolution Scintillator: $\mathrm{Ce}^{3+}$ Activated LaBr 3 . Appl. Phys. Lett. 2001, 79, 1573-1575.

20. Bernabei, R.; P. Belli; F. Montecchia; F. Nozzoli; A. d'Angelo; F. Cappella; A. Incicchitti; D. Prosperi; S. Castellano; R. Cerulli; C.J. Dai; V.I. Tretyak. Performances and Potentialities of a $\mathrm{LaCl}_{3}$ :Ce Scintillator. Nucl. Instrum. Methods Phys. Res., Sect. A 2005, 555, 270-281.

21. Hofstadter, R.; E. O'Dell; C. Schmidt. $\mathrm{CaI}_{2}$ and $\mathrm{CaI}_{2}$ (Eu) Scintillation Crystals. Rev. Sci. Instrum. 1964, 35, 246-247.

22. Shirasaki, Y.; G.J. Supran; M.G. Bawendi; V. Bulović. Emergence of Colloidal QuantumDot Light-Emitting Technologies. Nat. Photonics 2013, 7, 13.

23. Kang, Z.; Y. Zhang; H. Menkara; B.K. Wagner; C.J. Summers; W. Lawrence; V. Nagarkar. CdTe Quantum Dots and Polymer Nanocomposites for X-Ray Scintillation and Imaging. Appl. Phys. Lett. 2011, 98, 181914.

24. Lawrence, W.G.; S. Thacker; S. Palamakumbura; K.J. Riley; V.V. Nagarkar. Quantum Dot-Organic Polymer Composite Materials for Radiation Detection and Imaging. IEEE Trans. Nucl. Sci. 2012, 59, 215-221.

25. Dai, S.; S. Saengkerdsub; H.J. Im; A.C. Stephan; S.M. Mahurin. Nanocrystal - Based Scintillators for Radiation Detection. AIP Conf. Proc. 2002, 632, 220-224.

26. Osinski, M. Emerging Nanomaterials for Nuclear Radiation Detectors. MRS Proc. 2011, 1051, 1051-CC01-06. 
27. Withers, N.J.; K. Sankar; B.A. Akins; T.A. Memon; T. Gu; J. Gu; G.A. Smolyakov; M.R. Greenberg; T.J. Boyle; M. Osiński. Rapid Degradation of CdSe/ZnS Colloidal Quantum Dots Exposed to Gamma Irradiation. Appl. Phys. Lett. 2008, 93, 173101.

28. Stodilka, R.Z.; J.J.L. Carson; K. Yu; M.B. Zaman; C. Li; D. Wilkinson. Optical Degradation of CdSe/ZnS Quantum Dots upon Gamma-Ray Irradiation. J. Phys. Chem. C 2009, 113, 2580-2585.

29. Xie, C.; P. You; Z. Liu; L. Li; F. Yan. Ultrasensitive Broadband Phototransistors Based on Perovskite/Organic-Semiconductor Vertical Heterojunctions. Light: Sci. Appl. 2017, 6, e17023.

30. Cao, F.; D. Yu; X. Xu; B. Cai; Y. Gu; Y. Dong; Y. Shen; H. Zeng. Water-Assisted Synthesis of Blue Chip Excitable 2D Halide Perovskite with Green-Red Dual Emissions for White LEDs. Small Methods 0, 1900365.

31. Gu, L.; Z. Fan. Perovskite/Organic-Semiconductor Heterojunctions for Ultrasensitive Photodetection. Light Sci Appl 2017, 6, e17090.

32. Stoumpos, C.C.; C.D. Malliakas; J.A. Peters; Z. Liu; M. Sebastian; J. Im; T.C. Chasapis; A.C. Wibowo; D.Y. Chung; A.J. Freeman; B.W. Wessels; M.G. Kanatzidis. Crystal Growth of the Perovskite Semiconductor $\mathrm{CsPbBr}_{3}$ : A New Material for High-Energy Radiation Detection. Cryst. Growth. Des. 2013, 13, 2722-2727.

33. Zhang, Y.; R. Sun; X. Ou; K. Fu; Q. Chen; Y. Ding; L.J. Xu; L. Liu; Y. Han; A.V. Malko; X. Liu; H. Yang; O.M. Bakr; H. Liu; O.F. Mohammed. Metal Halide Perovskite Nanosheet for X-Ray High-Resolution Scintillation Imaging Screens. ACS Nano 2019, 13, 2520-2525. 34. Yakunin, S.; M. Sytnyk; D. Kriegner; S. Shrestha; M. Richter; G.J. Matt; H. Azimi; C.J. Brabec; J. Stangl; M.V. Kovalenko; W. Heiss. Detection of X-Ray Photons by SolutionProcessed Lead Halide Perovskites. Nat. Photonics 2015, 9, 444-449.

35. Heiss, W.; C. Brabec. Perovskites Target X-Ray Detection. Nat. Photonics 2016, 10, 288. 36. Wei, H.; Y. Fang; P. Mulligan; W. Chuirazzi; H.-H. Fang; C. Wang; B.R. Ecker; Y. Gao; M.A. Loi; L. Cao; J. Huang. Sensitive X-Ray Detectors Made of Methylammonium Lead Tribromide Perovskite Single Crystals. Nat. Photonics 2016, 10, 333-339.

37. Pan, W.; H. Wu; J. Luo; Z. Deng; C. Ge; C. Chen; X. Jiang; W.-J. Yin; G. Niu; L. Zhu; L. Yin; Y. Zhou; Q. Xie; X. Ke; M. Sui; J. Tang. $\mathrm{Cs}_{2} \mathrm{AgBiBr}_{6}$ Single-Crystal X-Ray Detectors with A Low Detection Limit. Nat. Photonics 2017, 11, 726-732.

38. Shrestha, S.; R. Fischer; G.J. Matt; P. Feldner; T. Michel; A. Osvet; I. Levchuk; B. Merle; S. Golkar; H. Chen; S.F. Tedde; O. Schmidt; R. Hock; M. Rührig; M. Göken; W. Heiss; G. 
Anton; C.J. Brabec. High-Performance Direct Conversion X-Ray Detectors Based on Sintered Hybrid Lead Triiodide Perovskite Wafers. Nat. Photonics 2017, 11, 436-440.

39. Kim, Y.C.; K.H. Kim; D.Y. Son; D.N. Jeong; J.Y. Seo; Y.S. Choi; I.T. Han; S.Y. Lee; N.G. Park. Printable Organometallic Perovskite Enables Large-Area, Low-Dose X-Ray Imaging. Nature 2017, 550, 87-91.

40. Liu, J.; B. Shabbir; C. Wang; T. Wan; Q. Ou; P. Yu; A. Tadich; X. Jiao; D. Chu; D. Qi; D. Li; R. Kan; Y. Huang; Y. Dong; J. Jasieniak; Y. Zhang; Q. Bao. Flexible, Printable Soft-XRay Detectors Based on All-Inorganic Perovskite Quantum Dots. Adv. Mater. 2019, 31, e1901644.

41. Birowosuto, M.D.; D. Cortecchia; W. Drozdowski; K. Brylew; W. Lachmanski; A. Bruno;

C. Soci. X-Ray Scintillation in Lead Halide Perovskite Crystals. Sci. Rep. 2016, 6, 37254.

42. Heo, J.H.; D.H. Shin; J.K. Park; D.H. Kim; S.J. Lee; S.H. Im. High-Performance Next-

Generation Perovskite Nanocrystal Scintillator for Nondestructive X-Ray Imaging. $A d v$.

Mater. 2018, 30, 1801743.

43. Mykhaylyk, V.B.; H. Kraus; M. Saliba. Bright and Fast Scintillation of Organolead Perovskite $\mathrm{MAPbBr}_{3}$ at Low Temperatures. Mater. Horiz. 2019, 6, 1740-1747.

44. Chen, Q.; J. Wu; X. Ou; B. Huang; J. Almutlaq; A.A. Zhumekenov; X. Guan; S. Han; L. Liang; Z. Yi; J. Li; X. Xie; Y. Wang; Y. Li; D. Fan; D.B.L. Teh; A.H. All; O.F. Mohammed; O.M. Bakr; T. Wu et al. All-Inorganic Perovskite Nanocrystal Scintillators. Nature 2018, 561, 88-93.

45. Niu, G.; W. Li; F. Meng; L. Wang; H. Dong; Y. Qiu. Study on the Stability of $\mathrm{CH}_{3} \mathrm{NH}_{3} \mathrm{PbI}_{3}$ Films and the Effect of Post-Modification by Aluminum Oxide in All-SolidState Hybrid Solar Cells. J. Mater. Chem. A 2014, 2, 705-710.

46. Leijtens, T.; G.E. Eperon; N.K. Noel; S.N. Habisreutinger; A. Petrozza; H.J. Snaith. Stability of Metal Halide Perovskite Solar Cells. Adv. Energy Mater. 2015, 5, 1500963-n/a. 47. Leguy, A.M.A.; Y. Hu; M. Campoy-Quiles; M.I. Alonso; O.J. Weber; P. Azarhoosh; M. van Schilfgaarde; M.T. Weller; T. Bein; J. Nelson; P. Docampo; P.R.F. Barnes. Reversible Hydration of $\mathrm{CH}_{3} \mathrm{NH}_{3} \mathrm{PbI}_{3}$ in Films, Single Crystals, and Solar Cells. Chem. Mater. 2015, 27, 3397-3407.

48. Hailegnaw, B.; S. Kirmayer; E. Edri; G. Hodes; D. Cahen. Rain on Methylammonium Lead Iodide Based Perovskites: Possible Environmental Effects of Perovskite Solar Cells. $J$. Phys. Chem. Lett. 2015, 6, 1543-1547. 
49. Zhaoning, S.; A. Antonio; W.S. C.; L.G. K.; P.A. B.; S. Ullrich; G. Michael; H.M. J. Perovskite Solar Cell Stability in Humid Air: Partially Reversible Phase Transitions in the $\mathrm{PbI}_{2}-\mathrm{CH}_{3} \mathrm{NH}_{3} \mathrm{I}-\mathrm{H}_{2} \mathrm{O}$ System. Adv. Energy Mater. 2016, 6, 1600846.

50. Kim, H.-S.; J.-Y. Seo; N.-G. Park. Material and Device Stability in Perovskite Solar Cells. ChemSusChem 2016, 9, 2528-2540.

51. Singh, S.; C. Li; F. Panzer; K.L. Narasimhan; A. Graeser; T.P. Gujar; A. Köhler; M.

Thelakkat; S. Huettner; D. Kabra. Effect of Thermal and Structural Disorder on the Electronic Structure of Hybrid Perovskite Semiconductor $\mathrm{CH}_{3} \mathrm{NH}_{3} \mathrm{PbI}_{3}$. J. Phys. Chem. Lett. 2016, 7 , 3014-3021.

52. Xue, J.; D. Yang; B. Cai; X. Xu; J. Wang; H. Ma; X. Yu; G. Yuan; Y. Zou; J. Song; H. Zeng. Photon-Induced Reversible Phase Transition in $\mathrm{CsPbBr}_{3}$ Perovskite. Adv. Funct. Mater. 2019, 29, 1807922.

53. Kirschner, M.S.; B.T. Diroll; P. Guo; S.M. Harvey; W. Helweh; N.C. Flanders; A. Brumberg; N.E. Watkins; A.A. Leonard; A.M. Evans; M.R. Wasielewski; W.R. Dichtel; X. Zhang; L.X. Chen; R.D. Schaller. Photoinduced, Reversible Phase Transitions in AllInorganic Perovskite Nanocrystals. Nat. Commun. 2019, 10, 504.

54. Nizamoglu, S.; H.V. Demir. Hybrid White Light Sources Based on Layer-by-Layer Assembly of Nanocrystals on Near-UV Emitting Diodes. Nanotechnology 2007, 18, 405702. 55. Lin, C.-H.; A. Verma; C.-Y. Kang; Y.-M. Pai; T.-Y. Chen; J.-J. Yang; C.-W. Sher; Y.-Z. Yang; P.-T. Lee; C.-C. Lin; Y.-C. Wu; S.K. Sharma; T. Wu; S.-R. Chung; H.-C. Kuo. Hybrid-Type White LEDs Based on Inorganic Halide Perovskite QDs: Candidates for Wide Color Gamut Display Backlights. Photonics Res. 2019, 7, 579-585.

56. Eidelman, L.G.; V.I. Goriletsky; V.G. Protsenko; A.V. Radkevich; V.V. Trofimenko. Automated Pulling from the Melt — An Effective Method for Growing Large Alkali Halide Single Crystals for Optical and Scintillation Applications. J. Cryst. Grwoth 1993, 128, 10591061.

57. Taranyuk, V.; A. Gektin; I. Kisil; A. Kolesnikov. NaI (Tl) and CsI (Tl) Scintillation Crystal Growth by Skull Method. J. Cryst. Grwoth 2011, 318, 820-822.

58. Luo, B.; S.B. Naghadeh; J.Z. Zhang. Lead Halide Perovskite Nanocrystals: Stability, Surface Passivation, and Structural Control. ChemNanoMat 2017, 3, 456-465.

59. Quan, L.N.; R. Quintero-Bermudez; O. Voznyy; G. Walters; A. Jain; J.Z. Fan; X. Zheng; Z. Yang; E.H. Sargent. Highly Emissive Green Perovskite Nanocrystals in a Solid State Crystalline Matrix. Adv. Mater. 2017, 29, 1605945-n/a. 
60. Mohammed, O.F. Outstanding Challenges of Zero-Dimensional Perovskite Materials. $J$. Phys. Chem. Lett. 2019, 5886-5888.

61. Seth, S.; A. Samanta. Fluorescent Phase-Pure Zero-Dimensional Perovskite-Related $\mathrm{Cs}_{4} \mathrm{PbBr}_{6}$ Microdisks: Synthesis and Single-Particle Imaging Study. J. Phys. Chem. Lett. 2017, 8, 4461-4467.

62. Seth, S.; A. Samanta. Photoluminescence of Zero-Dimensional Perovskites and Perovskite-Related Materials. J. Phys. Chem. Lett. 2017, 9, 176-183.

63. Saidaminov, M.I.; J. Almutlaq; S. Sarmah; I. Dursun; A.A. Zhumekenov; R. Begum; J. Pan; N. Cho; O.F. Mohammed; O.M. Bakr. Pure $\mathrm{Cs}_{4} \mathrm{PbBr}_{6}$ : Highly Luminescent ZeroDimensional Perovskite Solids. ACS Energy Lett. 2016, 1, 840-845.

64. De Bastiani, M.; I. Dursun; Y. Zhang; B.A. Alshankiti; X.-H. Miao; J. Yin; E. Yengel; E. Alarousu; B. Turedi; J.M. Almutlaq; M.I. Saidaminov; S. Mitra; I. Gereige; A. AlSaggaf; Y. Zhu; Y. Han; I.S. Roqan; J.-L. Bredas; O.F. Mohammed; O.M. Bakr. Inside Perovskites: Quantum Luminescence from Bulk $\mathrm{Cs}_{4} \mathrm{PbBr}_{6}$ Single Crystals. Chem. Mater. 2017, 29, 71087113.

65. Zhang, Y.; M.I. Saidaminov; I. Dursun; H. Yang; B. Murali; E. Alarousu; E. Yengel; B.A. Alshankiti; O.M. Bakr; O.F. Mohammed. Zero-Dimensional $\mathrm{Cs}_{4} \mathrm{PbBr}_{6}$ Perovskite Nanocrystals. J. Phys. Chem. Lett. 2017, 961-965.

66. Zhang, Y.; L. Sinatra; E. Alarousu; J. Yin; A.M. El-Zohry; O.M. Bakr; O.F. Mohammed. Ligand-Free Nanocrystals of Highly Emissive $\mathrm{Cs}_{4} \mathrm{PbBr}_{6}$ Perovskite. J. Phys. Chem. C 2018, 122, 6493-6498.

67. Yin, J.; H. Yang; K. Song; A.M. El-Zohry; Y. Han; O.M. Bakr; J.-L. Brédas; O.F. Mohammed. Point Defects and Green Emission in Zero-Dimensional Perovskites. J. Phys. Chem. Lett. 2018, 9, 5490-5495.

68. Ma, Z.; Z. Liu; S. Lu; L. Wang; X. Feng; D. Yang; K. Wang; G. Xiao; L. Zhang; S.A.T. Redfern; B. Zou. Pressure-Induced Emission of Cesium Lead Halide Perovskite Nanocrystals. Nat. Commun. 2018, 9, 4506.

69. Akkerman, Q.A.; S. Park; E. Radicchi; F. Nunzi; E. Mosconi; F. De Angelis; R. Brescia; P. Rastogi; M. Prato; L. Manna. Nearly Monodisperse Insulator $\mathrm{Cs}_{4} \mathrm{PbX}_{6}(\mathrm{X}=\mathrm{Cl}, \mathrm{Br}, \mathrm{I})$ Nanocrystals, Their Mixed Halide Compositions, and Their Transformation into $\mathrm{CsPbX}_{3}$ Nanocrystals. Nano Lett. 2017, 17, 1924-1930.

70. Palazon, F.; C. Urso; L. De Trizio; Q. Akkerman; S. Marras; F. Locardi; I. Nelli; M. Ferretti; M. Prato; L. Manna. Postsynthesis Transformation of Insulating $\mathrm{Cs}_{4} \mathrm{PbBr}_{6}$ 
Nanocrystals into Bright Perovskite $\mathrm{CsPbBr}_{3}$ through Physical and Chemical Extraction of CsBr. ACS Energy Lett. 2017, 2, 2445-2448.

71. Xu, J.; W. Huang; P. Li; D.R. Onken; C. Dun; Y. Guo; K.B. Ucer; C. Lu; H. Wang; S.M. Geyer. Imbedded Nanocrystals of $\mathrm{CsPbBr}_{3}$ in $\mathrm{Cs}_{4} \mathrm{PbBr}_{6}$ : Kinetics, Enhanced Oscillator Strength, and Application in Light - Emitting Diodes. Adv. Mater. 2017, 29, 1703703. 72. Qin, Z.; S. Dai; V.G. Hadjiev; C. Wang; L. Xie; Y. Ni; C. Wu; G. Yang; S. Chen; L. Deng; Q. Yu; G. Feng; Z.M. Wang; J. Bao. Revealing the Origin of Luminescence Center in 0D Cs $4 \mathrm{PbBr}_{6}$ Perovskite. Chem. Mater. 2019, 31, 9098-9104.

73. Riesen, N.; M. Lockrey; K. Badek; H. Riesen. On the Origins of the Green Luminescence in the "Zero-Dimensional Perovskite" $\mathrm{Cs}_{4} \mathrm{PbBr}_{6}$ : Conclusive Results from

Cathodoluminescence Imaging. Nanoscale 2019, 11, 3925-3932.

74. Lin, J.; L. Gomez; C. de Weerd; Y. Fujiwara; T. Gregorkiewicz; K. Suenaga. Direct Observation of Band Structure Modifications in Nanocrystals of $\mathrm{CsPbBr}_{3}$ Perovskite. Nano Lett. 2016, 16, 7198-7202.

75. Butkus, J.; P. Vashishtha; K. Chen; J.K. Gallaher; S.K.K. Prasad; D.Z. Metin; G.

Laufersky; N. Gaston; J.E. Halpert; J.M. Hodgkiss. The Evolution of Quantum Confinement in $\mathrm{CsPbr}_{3}$ Perovskite Nanocrystals. Chem. Mater. 2017.

76. Kang, B.; K. Biswas. Exploring Polaronic, Excitonic Structures and Luminescence in $\mathrm{Cs}_{4} \mathrm{PbBr}_{6} / \mathrm{CsPbBr}_{3}$. J. Phys. Chem. Lett. 2018, 9, 830-836.

77. Wang, Y.; D. Yu; Z. Wang; X. Li; X. Chen; V. Nalla; H. Zeng; H. Sun. Solution-Grown $\mathrm{CsPbBr}_{3} / \mathrm{Cs}_{4} \mathrm{PbBr}_{6}$ Perovskite Nanocomposites: Toward Temperature-Insensitive Optical Gain. Small 2017, 13, 1701587.

78. Galisteo-López, J.F.; M. Anaya; M.E. Calvo; H. Míguez. Environmental Effects on the Photophysics of Organic-Inorganic Halide Perovskites. J. Phys. Chem. Lett. 2015, 6, 22002205.

79. Protesescu, L.; S. Yakunin; M.I. Bodnarchuk; F. Krieg; R. Caputo; C.H. Hendon; R.X. Yang; A. Walsh; M.V. Kovalenko. Nanocrystals of Cesium Lead Halide Perovskites $\left(\mathrm{CsPbX}_{3}, \mathrm{X}=\mathrm{Cl}, \mathrm{Br}\right.$, and I): Novel Optoelectronic Materials Showing Bright Emission with Wide Color Gamut. Nano Lett. 2015, 15, 3692-3696.

80. Lin, E.C. Radiation Risk From Medical Imaging. Mayo Clin. Proc. 2010, 85, 1142-1146. 81. Blasse, G. Scintillator Materials. Chem. Mater. 1994, 6, 1465-1475.

82. Krämer, K.W.; P. Dorenbos; H.U. Güdel; C.W.E. van Eijk. Development and Characterization of Highly Efficient New Cerium Doped Rare Earth Halide Scintillator Materials. J. Mater. Chem. 2006, 16, 2773-2780. 
83. Zhang, F.; H. Zhong; C. Chen; X.-g. Wu; X. Hu; H. Huang; J. Han; B. Zou; Y. Dong. Brightly Luminescent and Color-Tunable Colloidal $\mathrm{CH}_{3} \mathrm{NH}_{3} \mathrm{PbX}_{3}(\mathrm{X}=\mathrm{Br}, \mathrm{I}, \mathrm{Cl}$ ) Quantum Dots: Potential Alternatives for Display Technology. ACS Nano 2015, 9, 4533-4542.

84. de Weerd, C.; J. Lin; L. Gomez; Y. Fujiwara; K. Suenaga; T. Gregorkiewicz.

Hybridization of Single Nanocrystals of $\mathrm{Cs}_{4} \mathrm{PbBr}_{6}$ and $\mathrm{CsPbBr}_{3}$. J. Phys. Chem. C 2017, 121, 19490-19496.

85. Kuwata, H.; H. Tamaru; K. Esumi; K. Miyano. Resonant Light Scattering from Metal Nanoparticles: Practical Analysis beyond Rayleigh Approximation. Appl. Phys. Lett. 2003, 83, 4625-4627.

86. Kresse, G.; J. Furthmüller. Efficient Iterative Schemes for Ab Initio Total-Energy Calculations Using A Plane-Wave Basis Set. Phys. Rev. B 1996, 54, 11169.

87. Kresse, G.; D. Joubert. From Ultrasoft Pseudopotentials to The Projector AugmentedWave Method. Phys. Rev. B 1999, 59, 1758.

88. Perdew, J.P.; K. Burke; M. Ernzerhof. Generalized Gradient Approximation Made Simple. Phys. Rev. Lett. 1996, 77, 3865. 